Acta Crystallographica Section B

Structural

Science

ISSN 0108-7681

\section{Lilianna Chęcińska, ${ }^{\mathrm{a} *}$ Simon Grabowsky, ${ }^{\text {b Magdalena }}$ Małecka, ${ }^{a}$ Agnieszka J. Rybarczyk-Pirek, ${ }^{a}$ Andrzej Jóźwiak, ${ }^{\text {c }}$ Carsten Paulmann ${ }^{\mathrm{d}, \mathrm{e}}$ and Peter Luger ${ }^{f}$}

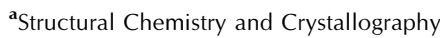
Group, University of Lodz, Tamka 12, Lodz 91 403, Poland, bschool of Biomedical, Biomolecular and Chemical Sciences, The University of Western Australia, Chemistry, M313, 35 Stirling Highway, Crawley, WA 6009, Australia, 'Department of Organic Chemistry, University of Lodz, Tamka 12, Lodz 91 403, Poland,

dMineralogisch-Petrographisches Institut, Universität Hamburg, Grindelallee 48, Hamburg 20 146, Germany, ${ }^{\mathbf{e}} \mathrm{c} / \mathrm{o}$ HASYLAB/DESY, Notkestrasse 85, Hamburg 22 607, Germany, and ${ }^{\mathrm{f}}$ Institut für Chemie und Biochemie/Anorganische Chemie, Freie Universität Berlin, Fabeckstr. 36a, Berlin 14 195, Germany

Correspondence e-mail: lilach@uni.lodz.pl
(C) 2011 International Union of Crystallography Printed in Singapore - all rights reserved

\title{
Experimental and theoretical electron-density study of three isoindole derivatives: topological and Hirshfeld surface analysis of weak intermolecular interactions
}

A combined experimental and theoretical study of three isoindole derivatives was made on the basis of a topological analysis of their electron-density distributions. Experimental electron densities were determined from high-resolution $\mathrm{X}$ ray diffraction data sets measured with synchrotron radiation at $100 \mathrm{~K}$, whereas theoretical calculations were performed using DFT methods at the B3LYP $6-311++\mathrm{G}(3 \mathrm{df}, 3 \mathrm{pd})$ level of approximation. Both experimental and theoretical models are in good agreement with each other. Since the analysed structures possess a variety of hydrogen-bonding interactions, weak intermolecular contacts of $\mathrm{C}-\mathrm{H} \cdots \mathrm{C}(\pi)$, $\mathrm{C}, \mathrm{N}(\pi) \cdots \mathrm{C}, \mathrm{N}(\pi)$ and $\mathrm{H} \cdots \mathrm{H}$ types were subject to our special interest and are discussed in detail. They were characterized quantitatively and qualitatively by topological properties using Bader's Atoms in Molecules theory and by mapping the electron-density distribution, electrostatic potential and a geometric function on the Hirshfeld surface. This way the forces and directions of intermolecular interactions as present on the molecular surfaces were depicted and described. These interactions not only guide crystal packing, but are likewise important for recognition processes involving (aza)isoindole fragments in a biological environment.

\section{Introduction}

The 3-substituted isoindol-1-ones have attracted our attention since they represent an important structural unit found in biologically active compounds, natural products and synthetic intermediates. Typical examples of pharmaceutically interesting molecules possessing anxiolytic activity are: pazinaclone (Wada \& Fukuda, 1991), pagoclone (Sorbera et al., 2001) and zopiclone (Anzini et al., 1996; Gotor et al., 1997). Moreover, the azaisoindol-1-one moiety also features in benzopyran derivatives used in the treatment of hypertension (American Home Products Corporation, 1997) and it may be useful as a synthetic precursor of simplified analogues of the INH-NAD adducts with potential interest as antituberculosis drugs (Broussy et al., 2005).

Herein we report the experimental and theoretical electrondensity studies of three isoindole derivatives: 3-hydroxy-2phenyl-2,3-dihydro-isoindol-1-one (I), 5-hydroxy-6-phenyl5,6-dihydro-pyrrolo[3,4-b]pyridin-7-one (II) and (3S)3-hydroxy-2,3-diphenyl-2,3-dihydro-pyrrolo[3,4-c]pyridine-1one (III) (see Fig. 1). High-resolution X-ray diffraction experiments using synchrotron radiation at low temperature allowed us to extract the precise electron-density distribution of (I)-(III) from the crystalline state, whereas DFT calculations verified the models obtained. The results were interpreted according to the 'Quantum Theory of Atoms in Molecules' (QTAIM) of Bader (1990), which is a powerful
Received 20 June 2011 Accepted 10 October 2011 
topological theory of chemical structure and reactivity. Based on the QTAIM theory, the electron density, $\rho(r)$, and its associated Laplacian, $\nabla^{2} \rho(r)$, provide important information on the chemical bonding of molecules. The partitioning procedure allows a separation of atomic basins from their neighbours and a subsequent integration of these basins gives atomic volumes and electron populations of the defined atoms. Hence, the qualitative and quantitative description of atoms and other sub-molecular fragments is possible.

As described above, the isoindole and azaisoindole skeletons are present in a large number of biologically active compounds. One important point to understand the reactivity and activity of biologically interacting compounds is to analyse the intermolecular contact pattern and thus reveal the potential of the scrutinized fragment to interact with e.g. enzymes or other types of proteins. The first step of a lowmolecular-weight ligand binding to a protein is the recognition process. It is guided by electrostatic complementarity and thus weak long-range intermolecular interactions (Naray-Szabo \& Ferenczy, 1995). There are, of course, several other important factors determining the biological activity of an agent, such as the electronic nature of the active centre, steric interactions of the entire protein-ligand aggregation, and solvent interactions in the aqueous biological environment. However, high-resolution electron-density measurements of single crystals give access to steric and detailed electronic as well as electrostatic properties of intermolecular interactions in the crystal environment (Coppens et al., 1999). It has been shown that these interactions can be assumed to be comparable in size to interactions under physiological conditions (Mladenovic et al., 2009). There are several conventional $\mathrm{O}-\mathrm{H} \cdots \mathrm{O}, \mathrm{N}-\mathrm{H} \cdots \mathrm{O}$ and $\mathrm{C}-\mathrm{H} \cdots \mathrm{O}$ contacts present in the crystal packing of (I)(III). Moreover, the extended aromatic system of the isoindole group gives the opportunity to also study weak $\mathrm{C}-\mathrm{H} \cdots \pi$, $\pi \cdots \pi$ and $\mathrm{H} \cdots \mathrm{H}$ interactions. There are only a few examples in the literature describing these kinds of weak interactions with electron-density means and quantifying them using topological analysis according to Bader (Munshi \& Row, 2006; Farrugia et al., 2009). We created Hirshfeld surfaces (Spackman \& Byrom, 1997; McKinnon et al., 2004) from the experimental electron density and plotted the electron density, the electrostatic potential and a geometric function on it. This way, it is possible to visualize the shape of the molecule as it is seen by the interacting neighbours and depict the directions and the strengths of the interactions. Different kinds of interactions and their impact on the complete packing can be identified by this method. Then, a systematic search in the density for their topological features can be performed and energetic values can be deduced.

\section{Experimental}

\subsection{X-ray diffraction experiments}

Crystals of (I)-(III) were obtained by slow evaporation of methanol solutions. High-resolution synchrotron data were measured at beamline F1 of the storage ring DORIS III at the HASYLAB/DESY, Hamburg, Germany. The experiments were carried out on a five-circle kappa-geometry Huber diffractometer equipped with a MAR165 CCD detector. In all cases crystals were cooled from ambient temperature to $100 \mathrm{~K}$ within $1.5 \mathrm{~h}$. The temperature was maintained at $100.0 \pm 0.2 \mathrm{~K}$

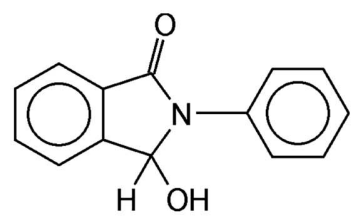

(a)

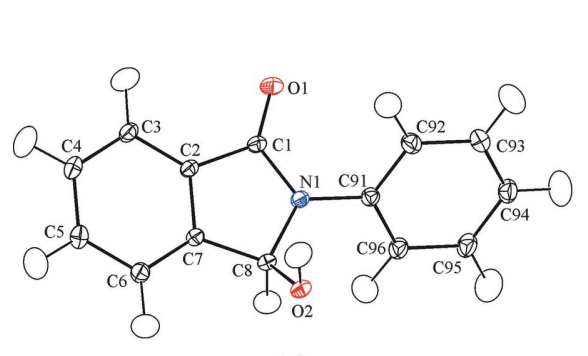

(d)

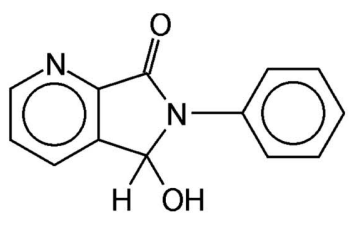

(b)

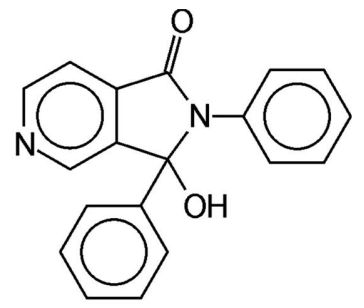

(c)

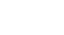

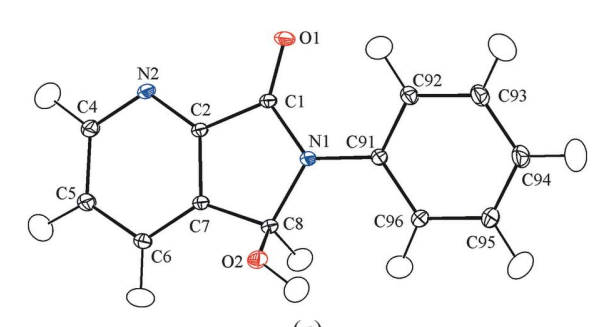

(e)

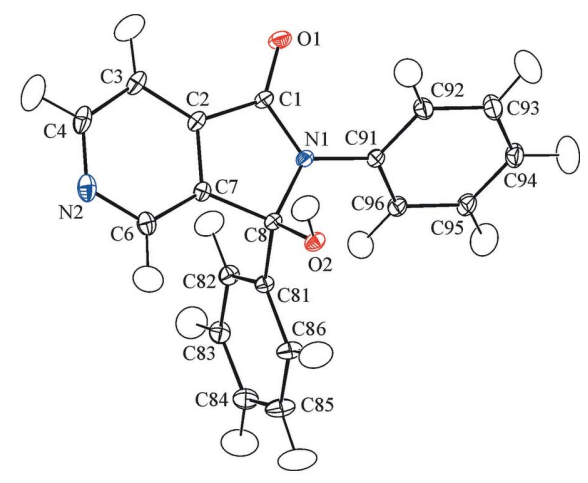

$(f)$

Figure 1

Diagrams $(a)-(c)$ and ORTEP (Burnett \& Johnson, 1996) representations $(d)-(f)$ of the molecular structures of (I), (II) and (III), taken from the multipole refinements (exp models), with atom-numbering schemes. The label for $\mathrm{H}$ atoms is the same as for their attached heavy atom. Anisotropic displacement ellipsoids are drawn at 50\% probability; ADPs for $\mathrm{H}$ atoms are obtained from the SHADE server (Madsen, 2006). 
Table 1

Crystal data, data collection, spherical and multipole refinement of (I)-(III).

Experiments were carried out at $100 \mathrm{~K}$ using an Huber diffractometer. Data collection used $\varphi$ scans.

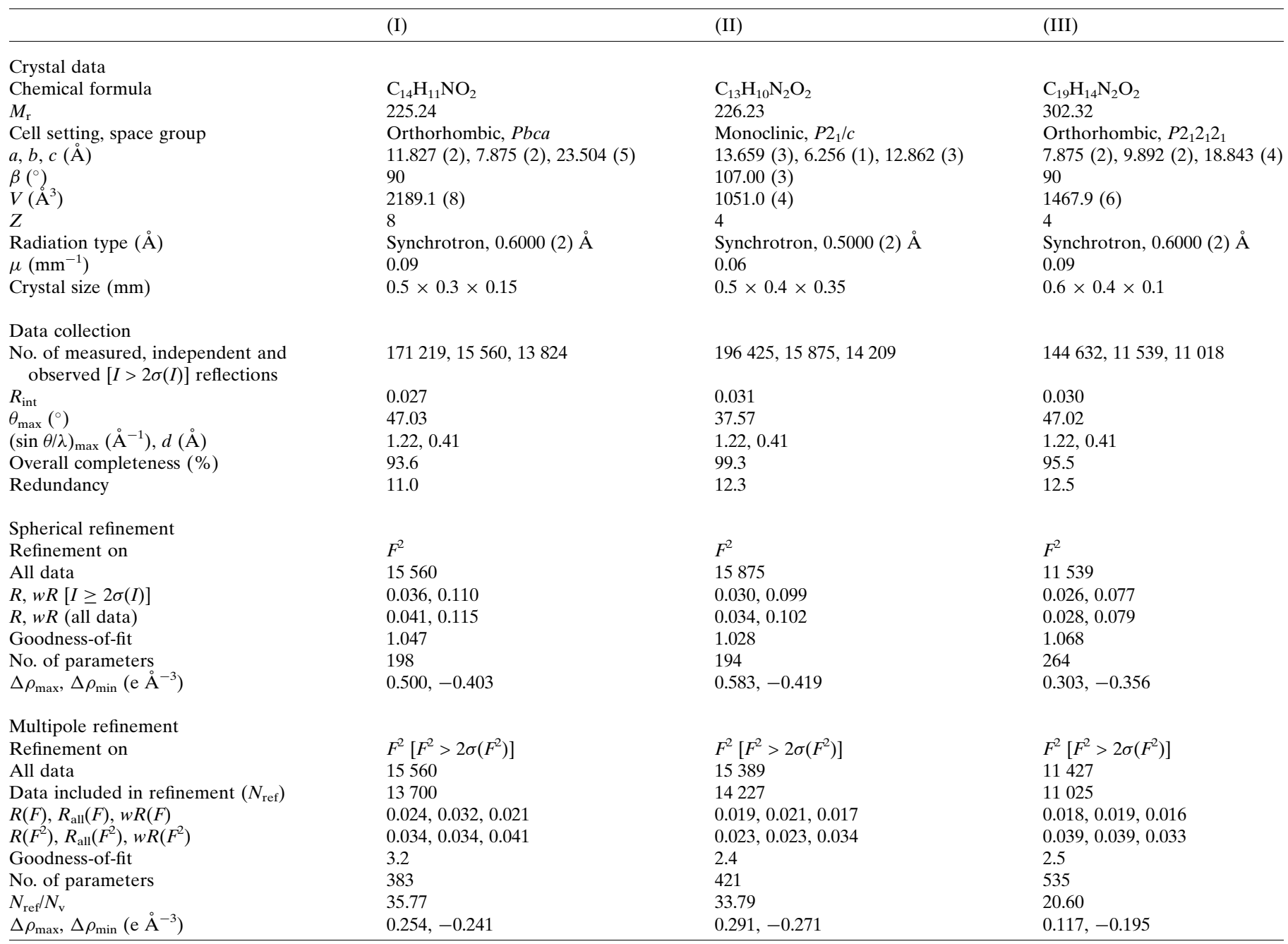

Computer programs used: MarF1D3 (Paulmann \& Morgenroth, 2006), XDS (Kabsch, 1993, 2010), SHELXS97 (Sheldrick, 2008$)$, XD2006 (Volkov et al., 2006).

over the whole experiment with an Oxford Cryosystem $N_{2}$ gasstream cooling device. The wavelengths of 0.6000 (2) and 0.5000 (2) ^̊ were used for (I)/(III) and (II), respectively.

An integration of all measured frames was performed with the program XDS (Kabsch, 1993, 2010). Subsequently, all datasets were sorted, merged and cut to the resolution $\sin \theta / \lambda$ $=1.22 \AA^{-1}$ (or in direct space $d=0.41 \AA$ ) using XPREP (Bruker, 2005). Further details of crystal data and measurement conditions are given in Table 1 .

\subsection{Refinement strategy}

The molecular structures of (I)-(III) were solved and spherically refined using SHELX97 (Sheldrick, 2008). The absolute configuration of the C8 atom of (III) - which is the only one of the three compounds crystallizing in a noncentrosymmetric space group and thus not as a racemic mixture - was determined as $(S)$ on data measured with copper radiation (supplementary material ${ }^{\mathbf{1}}$ ). The final independent atom models (IAM) were subsequently entered as starting parameters into the aspherical atom treatment. The multipole refinements, based on the Hansen-Coppens formalism (Hansen \& Coppens, 1978), were carried out on $F^{2}\left[\left(F^{2}\right)\right.$ $\left.>2 \sigma\left(F^{2}\right)\right]$ with the full-matrix LSQ program $X D L S M$ of the $X D 2006$ program package (Volkov et al., 2006). For all non-H atoms the hexadecapolar level of the multipolar expansion was used, whereas for all $\mathrm{H}$-atoms cylindrical contributions up to quadrupolar level were refined. Moreover, 13 and 15 kappa parameters were introduced for the non-H atoms in (I) and (II)/(III), respectively. Additionally, $\kappa$ was kept constant at 1.13 for the $\mathrm{H}$ atoms. A local mirror symmetry $(m)$ was applied to non-H atoms, except the asymmetric C8 atom. The multipole parameters of chemically equivalent atoms were

\footnotetext{
${ }^{\mathbf{1}}$ Supplementary data for this paper are available from the IUCr electronic archives (Reference: SN5107). Services for accessing these data are described at the back of the journal.
} 
constrained to be the same. This was applied to the $\mathrm{C}$ atoms within the isoindole moiety of (I), where C5, C6 were set like $\mathrm{C} 4, \mathrm{C} 3$, and within the phenyl rings of all three compounds, where $\mathrm{C} 85 / \mathrm{C} 86$ and $\mathrm{C} 95 / \mathrm{C} 96$ were treated the same as $\mathrm{C} 83 /$ $\mathrm{C} 82$ and $\mathrm{C} 93 / \mathrm{C} 92$. A similar treatment was applied to the $\mathrm{H}$ atoms: $\mathrm{H} 4, \mathrm{H} 5$ and $\mathrm{H} 6$ were constrained to $\mathrm{H} 3$ only in (I), H83-H86 and H93-H96 were set like H82 and H92.

The distances $\mathrm{O}-\mathrm{H}, \mathrm{N}-\mathrm{H}$ and $\mathrm{C}-\mathrm{H}$ were elongated to mean values from neutron-diffraction experiments according to the International Tables of X-ray Crystallography (Allen et al., 2006). On the final stage of all three refinements anisotropic displacement parameters (ADPs) for $\mathrm{H}$ atoms were obtained from the SHADE approach (Madsen, 2006). The calculated $\mathrm{H}$-atom ADPs were used as fixed parameters in the final cycles of all refinements, however, all remaining parameters were co-refined simultaneously retaining all chemical constraints and imposed symmetries. Obtained residual density plots in the plane of the (aza)isoindole moiety for (I)(III) are displayed in Fig. S1 of the supplementary material. Conventional figures of merit for the spherical and multipole refinements are summarized in Table 1. Topological and integrated atomic properties from the multipole models were obtained using the XDPROP and TOPXD subprograms implemented in the $X D 2006$ package.

\subsection{Theoretical calculations}

The molecular geometries from the multipole models of (I)-(III) were entered into single-point calculations with $D F T$ methods [B3LYP $\mid 6-311++\mathrm{G}(3 \mathrm{df}, 3 \mathrm{pd})]$ ( $t h-s p$ model) to allow a comparison with the experimental results.

Additionally, single-point calculations were also performed for dimers and trimers of (II) to verify the existence of the weak intermolecular interactions found in the crystalline state.

All computations were performed using GAUSSIAN03 (Frisch et al., 2004). The theoretical wavefunctions obtained were evaluated with the program AIM2000 (Biegler-König \& Schönbohm, 2002) to obtain the topological parameters and AIMALL (Keith, 2009) was used to integrate atomic properties.

\section{Results and discussion}

\subsection{Description of structures, topological parameters and atomic properties}

The molecular structure of the three isoindole derivatives derived from the high-resolution synchrotron data are displayed as ORTEP representations in Figs. $1(d)-(f)$. The atomic numbering scheme of all analysed molecules was chosen to be identical. The main part of the investigated structures is the 3-hydroxy-isoindol-1-one skeleton substituted by a phenyl group at the $\mathrm{N} 1$ atom. In (II) and (III), at the position $7 / 5$ of the isoindole moiety, the carbon atom $\mathrm{C} 3 / \mathrm{C} 5$ from (I), respectively, is replaced by the $\mathrm{N} 2$ atom, giving azaisoindole derivatives. Additionally in (III) a second phenyl substituent is attached to the asymmetric $\mathrm{C} 8$ atom.
The planar five- and six-membered rings of the (aza)isoindole system are joined together at the $\mathrm{C} 2-\mathrm{C} 7$ bond edge producing a dihedral angle of $2.09(1) / 1.76(1) / 0.87(1)^{\circ}$ for (I)/(II)/(III), respectively. The condensed nine-membered (aza)isoindole ring might be considered planar in all structures. The least-squares plane of the (aza)isoindole ring defines a dihedral angle of 46.79 (1)/20.01 (1)/55.98 (1) ${ }^{\circ}$ with a best plane of the phenyl ring attached to the $\mathrm{N} 1$ atom for (I)(III), respectively. Moreover, the second phenyl ring in structure (III), attached to the asymmetric C8 atom, makes angles of $89.70(1) / 77.42(1)^{\circ}$ with the azaisoindole and phenyl C91-C96 rings. Full details of bond lengths and angles are given in the supplementary material. An analysis of the geometry within the (aza)isoindole fragment of the investigated molecules shows the expected tendencies and no further discussion is needed.

To obtain a quantitative description of the electronic structures of (I)-(III), a full topological analysis was performed on the basis of the theory of Atoms in Molecules (AIM). Table S1 lists the total electron density at the bondcritical points (b.c.p.s) and the associated Laplacian for all connections between non- $\mathrm{H}$ atoms for the experimental multipole model compared with the theoretical model th-sp. Comparing experiment with theory for all three molecules, the polar bond $\mathrm{C} 1-\mathrm{O} 1$ shows a typical discrepancy for its Laplacian, which is known in the literature as the limited flexibility of radial functions used in the multipole model (Volkov et al., 2000; Volkov \& Coppens, 2001). Apart from this feature of the polar bond, generally there is great similarity between the experimental and theoretical topological parameters.

From Bader's AIM theory it was also possible to obtain atomic properties in terms of volumes and charges from integration over the volumes enclosed by the zero-flux surfaces of the electron-density gradient-vector field. The precision of the numerical integrations of (I)-(III) was judged on the basis of a maximum Lagrangian value of 0.002 , which in practice is considered to be acceptable (Volkov et al., 2000; Grabowsky et al., 2009). Moreover, the integration procedure was validated in terms of the sum of atomic volumes, which reproduced the experimental unit-cell volume within $0.01 \%$ in all three cases. Similarly, the sum of charges differs only $0.03 e$ from electroneutrality.

From the results recorded in Table $\mathrm{S} 2$ it is clear that major discrepancies between experiment and theory appear for carbonyl and hydroxyl groups (O1, C1 and $\mathrm{O} 2)$ and the $\mathrm{N} 2$ atom. It is worth mentioning that these groups and atoms are involved in medium-strength hydrogen bonds, which are described in $\$ 3.3$.

\section{2. $\pi$-delocalization}

One of the purposes of this paper is to analyse the weak interactions with a contribution of $\pi$-electrons. Considering such types of interactions, knowledge about the $\pi$-electron delocalization effect within the investigated (aza)isoindole 
Table 2

HOMA index and experimental ellipticity values for bonds within the $\pi$-delocalized systems.

Ellipticities are given as average values for $\mathrm{C}-\mathrm{C}$ and $\mathrm{N}-\mathrm{C}$ types of bonds within the rings, except for the $\mathrm{N} 1-\mathrm{C} 1-\mathrm{O} 1$ fragment

\begin{tabular}{|c|c|c|c|c|c|c|}
\hline & \multicolumn{3}{|c|}{ HOMA } & \multicolumn{3}{|l|}{ Ellipticity } \\
\hline & (I) & (II) & (III) & (I) & (II) & (III) \\
\hline $\begin{array}{l}\text { Six-membered ring of } \\
\text { (aza)isoindole moiety }\end{array}$ & 0.966 & 0.860 & 0.983 & $\varepsilon_{\mathrm{C}-\mathrm{C}}=0.22$ & $\begin{array}{l}\varepsilon_{\mathrm{C}-\mathrm{C}}=0.23 \\
\varepsilon_{\mathrm{N}-\mathrm{C}}=0.15\end{array}$ & $\begin{array}{l}\varepsilon_{\mathrm{C}-\mathrm{C}}=0.24 \\
\varepsilon_{\mathrm{N}-\mathrm{C}}=0.24\end{array}$ \\
\hline $\mathrm{N} 1-\mathrm{C} 1-\mathrm{O} 1$ fragment & 0.841 & 0.780 & 0.886 & $\begin{array}{l}\varepsilon_{\mathrm{N} 1-\mathrm{C} 1}=0.32 \\
\varepsilon_{\mathrm{C} 1-\mathrm{O} 1}=0.12\end{array}$ & $\begin{array}{l}\varepsilon_{\mathrm{N} 1-\mathrm{C} 1}=0.23 \\
\varepsilon_{\mathrm{C} 1-\mathrm{O} 1}=0.09\end{array}$ & $\begin{array}{l}\varepsilon_{\mathrm{N} 1-\mathrm{C} 1}=0.43 \\
\varepsilon_{\mathrm{C} 1-\mathrm{O} 1}=0.07\end{array}$ \\
\hline $\begin{array}{l}\text { Phenyl ring C91-C96 } \\
\text { Phenyl ring C81-C86 }\end{array}$ & $\begin{array}{l}0.968 \\
-\end{array}$ & $\begin{array}{l}0.916 \\
-\end{array}$ & $\begin{array}{l}0.968 \\
0.964\end{array}$ & $\varepsilon_{\mathrm{C}-\mathrm{C}}=0.27$ & $\varepsilon_{\mathrm{C}-\mathrm{C}}=0.21$ & $\begin{array}{l}\varepsilon_{\mathrm{C}-\mathrm{C}}=0.17 \\
\varepsilon_{\mathrm{C}-\mathrm{C}}=0.20\end{array}$ \\
\hline
\end{tabular}

molecules is needed. On geometric grounds, the index of aromaticity HOMA can be easily applied as a reliable measure of $\pi$-electron delocalization. The formula for HOMA is as follows (Krygowski, 1993)

$$
\mathrm{HOMA}=1-\frac{1}{n} \sum_{j=1}^{n} \alpha_{i}\left(R_{\mathrm{opt}, i}-R_{j}\right)^{2},
$$

where $n$ is the number of bonds taken into the summation, $\alpha_{i}$ is an empirical constant $\left(\alpha_{\mathrm{CC}}=257.7 ; \alpha_{\mathrm{CN}}=93.52 ; \alpha_{\mathrm{CO}}=157.38\right)$ chosen to give HOMA $=0$ for a non-aromatic system and HOMA $=1$ for a system with all bonds equal to the optimal value $R_{\text {opt }}$ assumed to be realised for full aromatic systems $\left(R_{\mathrm{opt}, \mathrm{CC}}=1.388 \AA ; R_{\mathrm{opt}, \mathrm{CN}}=1.334 \AA ; R_{\mathrm{opt}, \mathrm{CO}}=1.265 \AA\right)$. The individual bond lengths are represented by $R_{i}$.

Since the HOMA index can be used for any $\pi$-electron systems, not only for rings but also for the analysis of fragments of the ring (Szatyłowicz et al., 2011), and for non-planar systems (Palusiak \& Krygowski, 2009), we applied it to our following systems: typical planar rings as the phenyl substituents and the six-membered part of the isoindole moiety as well as to the $\mathrm{O} 1-\mathrm{C} 1-\mathrm{N} 1$ part of the structure where electronic delocalization was expected. It can be seen from Table 2 that the aromatic character of the phenyl rings is represented by the calculated HOMA values as expected, because they are close to unity. Moreover, the HOMA values for the sixmembered rings of the (aza)isoindole moieties and to a lesser degree also the $\mathrm{N} 1-\mathrm{C} 1-\mathrm{O} 1$ fragment are close to those of the phenyl rings, indicating that the isoindole group exhibits a significant amount of $\pi$-delocalization in all three compounds.

Considering the topology of the delocalized fragments, the aromatic $\mathrm{C}-\mathrm{C}$ bonds within the phenyl groups (C81-C86, C91-C96) are of a similar strength, with a small range of values observed for $\rho(r)$ and its Laplacian at the b.c.p.s (1.95$2.07 \mathrm{e} \AA^{-3} ; 15.0-18.8 \mathrm{e}^{-5}$ ) for all three analysed molecules. These values correspond well with those found for $\mathrm{C}-\mathrm{C}$ bonds inside the six-membered part of the (aza)isoindole moiety $\left(2.00-2.15\right.$ e $\left.\AA^{-3}, 15.2-21.2 \mathrm{e} \AA^{-5}\right)$, which confirms its electronic delocalization.

Furthermore, the degree of aromaticity in a particular chemical bond can be represented by its bond ellipticity: $\left(\lambda_{1} / \lambda_{2}\right)-1$. It is zero for a perfectly isolated single bond and 0.23 for a 1.5fold bond in benzene (Bader et al., 1983). The values for the $\mathrm{C}-\mathrm{C}$ bonds in the phenyl groups in (I)-(III) and for the six-membered ring in the (aza)isoindole moiety are close to 0.23 (see Table 2) and uniformly distributed between the $\mathrm{C}-\mathrm{C}$ bonds, clearly indicating $\pi$-delocalization.

In summary, both the phenyl and (aza)isoindole fragments clearly contain an extended delocalized $\pi$-system, which can serve as an acceptor for intermolecular interactions with positively polarized $\mathrm{H}$ atoms or which can be involved in $\pi \cdots \pi$-stacking interactions.

\subsection{Intermolecular interactions}

Owing to various intermolecular interactions, (I)-(III) form mechanically stable and resistable crystals. From geometric criteria, $\mathrm{O}-\mathrm{H} \cdots \mathrm{O}, \mathrm{O}-\mathrm{H} \cdots \mathrm{N}$ and $\mathrm{C}-\mathrm{H} \cdots \mathrm{O}$ hydrogen bonds were found in the crystal packing of (I)-(III) which give rise to the formation of infinite chains (see Table 3).

In (I) the hydrogen bond $\mathrm{O} 2-\mathrm{H} 2 \cdots \mathrm{O} 1$ produces an infinite zigzag chain running along the [010] direction, whose first-level graph-set descriptor (Bernstein et al., 1995) is C6. Additionally, the two weak intermolecular $\mathrm{C}-\mathrm{H} \cdots \mathrm{O}$ contacts $\mathrm{C} 6-\mathrm{H} 6 \cdots \mathrm{O} 1$ and $\mathrm{C} 94-\mathrm{H} 94 \cdots \mathrm{O} 2$ produce the chain patterns $C 6$ and $C 8$, running parallel to the [100] and [010] direction, respectively. In the azaisoindole derivative (II) the $\mathrm{O} 2-\mathrm{H} 2 \cdots \mathrm{N} 2$ hydrogen-bond generates an infinite $\mathrm{C} 6$ chain along the [001] direction. The packing of (II) also involves the weak hydrogen bonds $\mathrm{C} 8-\mathrm{H} 8 \cdots \mathrm{O} 1$ and $\mathrm{C} 96-\mathrm{H} 96 \cdots \mathrm{O} 1$, which create chain $C 5$ and $C 6$ motifs, respectively, joining the same molecules as the aforementioned $\mathrm{O}-\mathrm{H} \cdots \mathrm{N}$ hydrogen bond. The molecules of the azaisoindole derivative (III) are linked by the $\mathrm{O} 2-\mathrm{H} 2 \cdots \mathrm{O} 1$ hydrogen bond, which is responsible for the formation of an infinite zigzag $\mathrm{C} 6$ chain motif along the [100] direction.

Table 3 lists all the geometric, topological and energetic properties characterizing the hydrogen bonds. The $\mathrm{O}-\mathrm{H} \cdots \mathrm{O}$ and $\mathrm{O}-\mathrm{H} \cdots \mathrm{N}$ interactions are likewise medium-strength hydrogen bonds as the donor $\cdots$ acceptor distance is $\sim 2.7$ $2.8 \AA$, the electron density at the $\mathrm{H}$ - . acceptor b.c.p. is above $0.2 \mathrm{e} \AA^{-3}$, the hydrogen-bond energies are around $-40 \mathrm{~kJ} \mathrm{~mol}^{-1}$ and the ratio of the potential and the kinetic energy densities is close to unity. The $\mathrm{C}-\mathrm{H} \cdots \mathrm{O}$ interactions are much weaker, but still directed as can be seen from the topological parameters. An $\mathrm{H}$...O b.c.p. was found, but its electron density is close to zero, the corresponding Laplacian below $1 \mathrm{e} \AA^{-5}$, the hydrogen-bond energies above $-10 \mathrm{~kJ} \mathrm{~mol}^{-1}$, and the kinetic energy density dominates the potential energy density. It is clear from these parameters that medium-strength interactions can easily be discerned from weak ones, but also that both are directed hydrogen bonds. 
Table 3

Hydrogen-bonding geometries (in $\AA^{\circ},{ }^{\circ}$ ), topological parameters at the hydrogen $\cdots$ acceptor b.c.p.: electron density $\rho(r)\left(\right.$ in e $\left.\AA^{-3}\right)$ and its Laplacian $\nabla^{2} \rho(r)$ (in e $\AA^{-5}$ ), energies (in $\mathrm{kJ} \mathrm{mol}^{-1}$ ) and local energy densities (in $\mathrm{kJ} \mathrm{mol}^{-1}$ per atomic unit volume) obtained from the multipole model (exp) of (I)-(III).

$G(r)$ - kinetic energy density at the b.c.p.; $V(r)$ - potential energy density at the b.c.p.; $H(r)$ - total energy density at the b.c.p.; $E_{\mathrm{HB}}-$ estimated hydrogen-bond energy from the relation $E_{\mathrm{HB}}=\frac{1}{2} V(r) ; E_{\mathrm{HBgeom}}$ - estimated hydrogen-bond energy from the distance-dependent relation (Espinosa et al., 1998); $|V| / G-$ ratio of the potential and kinetic energy densities at the b.c.p. (Espinosa et al., 2002).

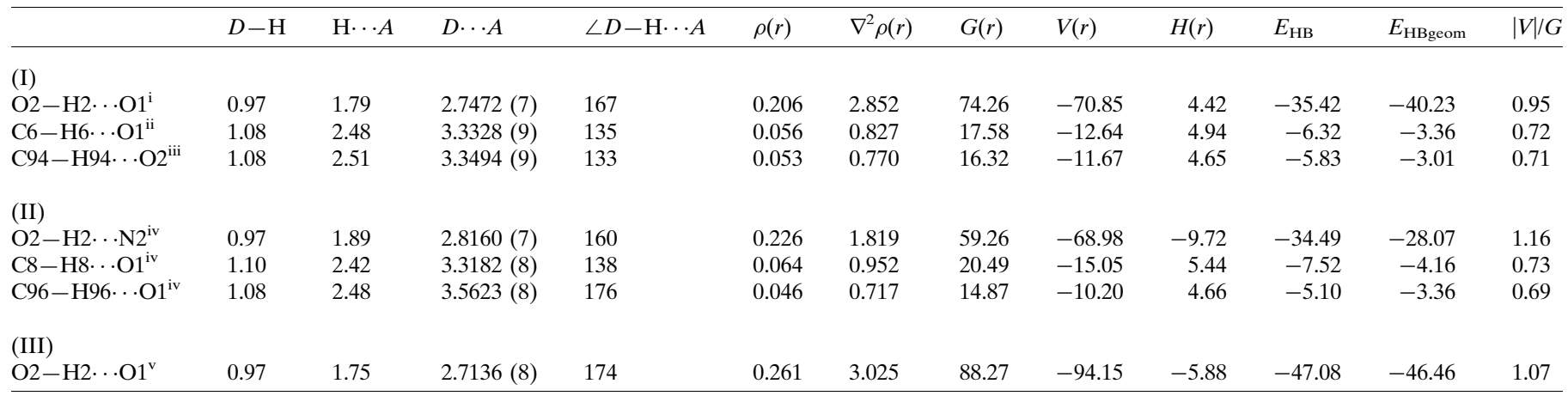

Symmetry codes: (i) $\frac{1}{2}-x, \frac{1}{2}+y, z$; (ii) $-\frac{1}{2}+x, \frac{1}{2}-y,-z$; (iii) $-x,-\frac{1}{2}-y, \frac{1}{2}-z$; (iv) $x, \frac{1}{2}-y, \frac{1}{2}+z$; (v) $-\frac{1}{2}+x, \frac{1}{2}-y, 1-z$.

To obtain an overview of the complete intermolecular interaction pattern of the scrutinized compounds and to analyse how the hydrogen bonds guide the packing scheme, the properties mapped on molecular surfaces of the compounds should be analysed. These molecular surfaces are defined as the outer contour of the space the molecules consume and therefore represent the area other molecules come in contact with in the first step of a reaction or close interaction. As detailed in the introductory part, this is especially important for biologically interacting systems as the ligand-enzyme recognition step takes place via the molecular surfaces. There are several ways to define the molecular surface (Bader et al., 1987; Connolly, 1983). We decided to calculate Hirshfeld surfaces (Spackman \& Byrom, 1997; McKinnon et al., 2004) as a choice of molecular surfaces because they have been proven to picture intermolecular
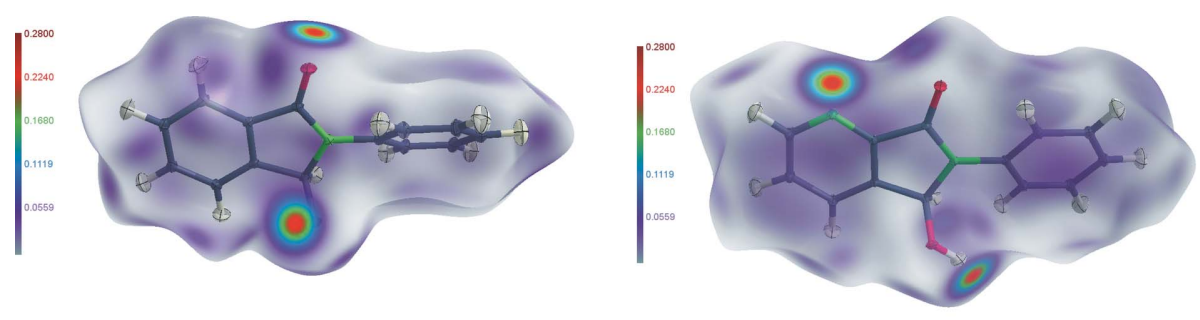

(a)

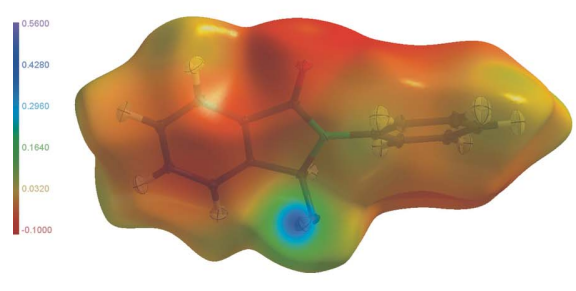

(d) (b)

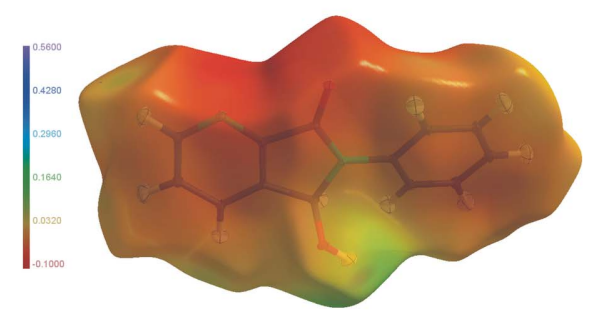

(e)

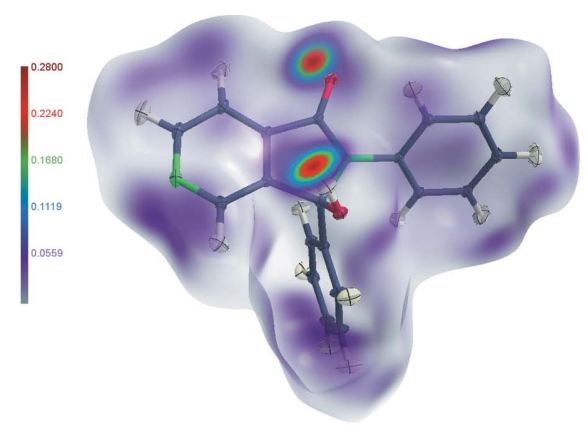

(c)
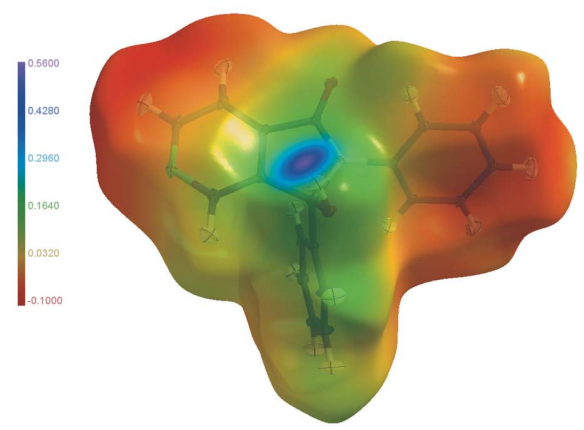

$(f)$

Figure 2

Hirshfeld surfaces generated from the experimental spherical electron density with the total experimental aspherical electron density (in e $\AA^{-3}$ ) after multipole modelling mapped onto them: $(a)(\mathrm{I}),(b)(\mathrm{II}),(c)(\mathrm{III})$; with the experimental electrostatic potential (in e $\left.\AA^{-1}\right)$ mapped onto them: $(d)(\mathrm{I}),(e)$ (II), (f) (III); program for visualization is MolecoolQt (Hübschle \& Dittrich, 2011). 
interactions in the crystal packing very reliably (Spackman et al., 2008; Weber et al., 2011). Fig. 2 depicts the Hirshfeld surfaces of (I)-(III) computed from the spherical electron densities with XD2006 (Volkov et al., 2006) and visualized with MolecoolQt (Hübschle \& Dittrich, 2011). By mapping the total experimental aspherical electron density on the Hirshfeld surfaces (Figs. $2 a-c$ ), covalent contributions to the interactions can be made visible. Donor and acceptor atoms of the $\mathrm{O}-\mathrm{H} \cdots \mathrm{O} / \mathrm{N}$ hydrogen bonds comprise deeply coloured regions on the surface and thus show a directed and localized interaction, which manifests itself in the total electron density. In addition, it can already be seen here that aromatic ring regions also show some electron density on the Hirshfeld surface. Figs. 2(d)-(f) show the experimental electrostatic potential mapped on the Hirshfeld surfaces, visualizing the electrostatic contributions to the intermolecular interactions. In the electrostatic potential - in contrast to the electron density - directed and localized contacts can only be found at the donor $\mathrm{H}$ atoms being strongly positively polarized, but not at the acceptor $\mathrm{N}$ or $\mathrm{O}$ atoms. They are clearly negatively polarized and thus match the principle of electrostatic complementarity guiding crystal packing in general (NaraySzabo \& Ferenczy, 1995), but the region of negative potential is much broader, i.e. not localized and directed. Another very interesting observation is that the regions around the aromatic rings are likewise negatively polarized, meaning that the $\pi$ electron clouds also act as acceptors for intermolecular interactions. This way of mapping physical properties on the Hirshfeld surfaces shows which forces act on the molecules in contact with each other.

To identify individual types of contacts, it is suitable to go back to a geometric function which makes these differentiations possible. The function $d_{\text {norm }}$ is a ratio including the distances of any surface point to the nearest interior $\left(d_{\mathrm{i}}\right)$ and exterior $\left(d_{\mathrm{e}}\right)$ atom and the van der Waals radii of the atoms $\left(r^{\mathrm{vdW}}\right)$ (McKinnon et al., 2007)

$$
d_{\mathrm{norm}}=\frac{d_{i}-r_{i}^{\mathrm{vdW}}}{r_{i}^{\mathrm{vdW}}}+\frac{d_{e}-r_{e}^{\mathrm{vdW}}}{r_{e}^{\mathrm{vdW}}}
$$

If $d_{\text {norm }}$ is negative the sum of $d_{\mathrm{i}}$ and $d_{\mathrm{e}}$, i.e. the contact distance, is shorter than the sum of the atoms' van der Waals radii. This is considered to be a close contact and is coloured red in Figs. 3(a)-(c), where $d_{\text {norm }}$ is plotted on the Hirshfeld surfaces of (I)-(III) using the program CrystalExplorer (Spackman \& Jayatilaka, 2009). A white-coloured region
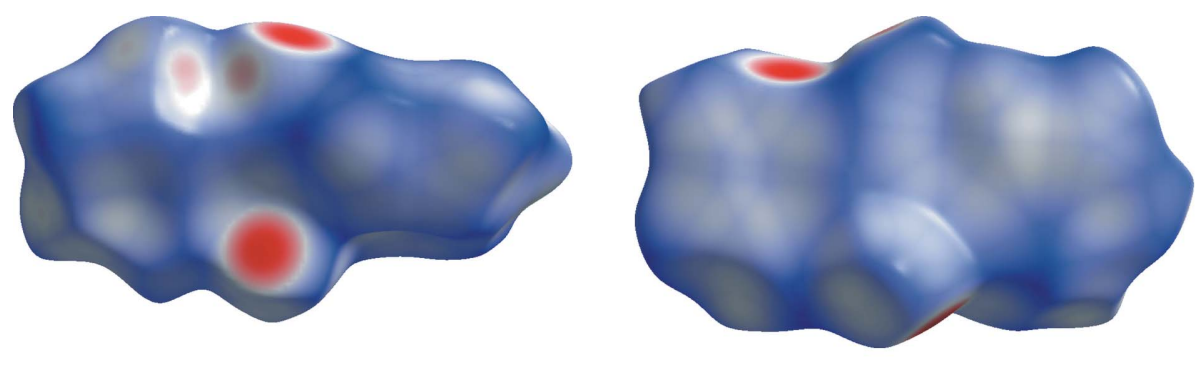

(a)

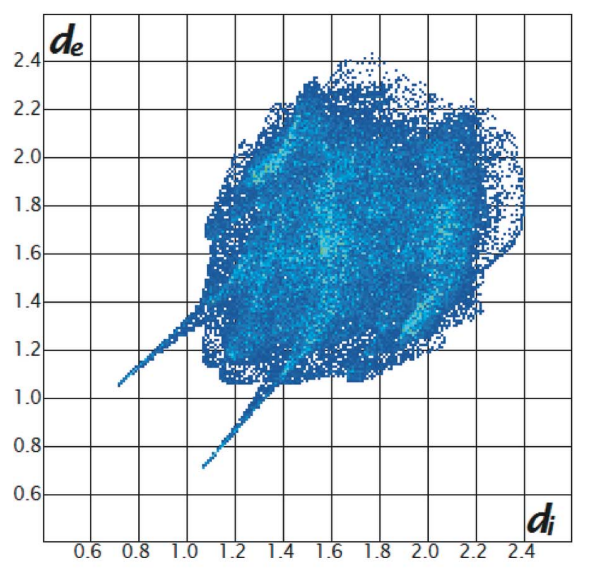

(d) (b)

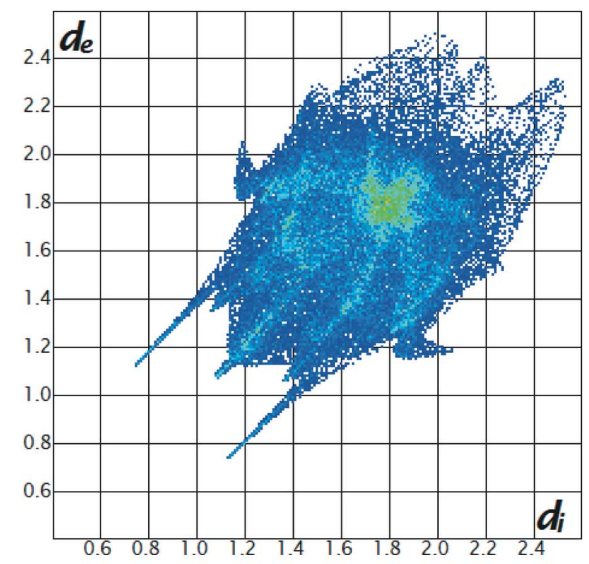

(e)

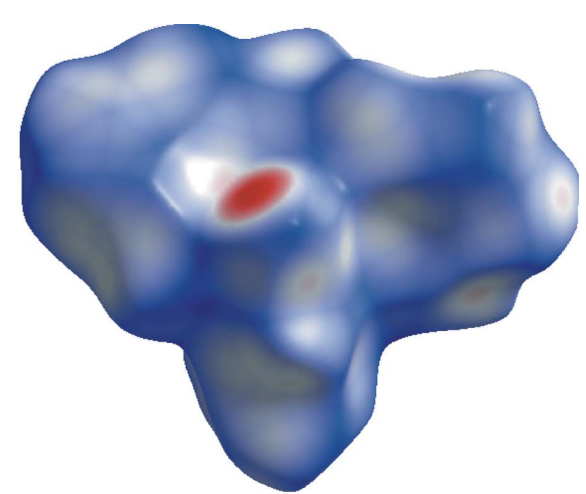

(c)

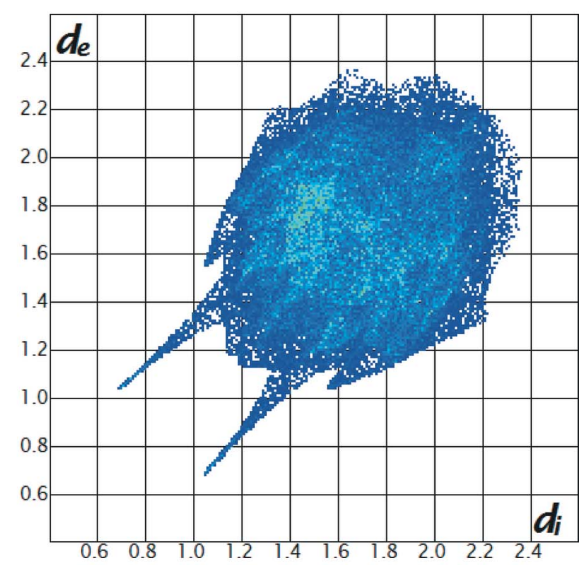

$(f)$

Figure 3

Hirshfeld surfaces and corresponding fingerprint plots generated from an atomic spherically averaged electron density using the program CrystalExplorer (Spackman \& Jayatilaka, 2009). The colour code on the Hirshfeld surfaces represents the geometrical function $d_{\text {norm }}$ : $(a)$ (I) scale of $d_{\text {norm }}$ is -0.69 to $1.1,(b)$ (II) scale of $d_{\text {norm }}$ is -0.64 to 1.2 , and (c) (III) scale of $d_{\text {norm }}$ is -0.73 to 1.1 . Negative values of $d_{\text {norm }}$ indicating areas with contact distances shorter than the sum of the van der Waals radii are coloured red. In the fingerprint plots of $(d)$ (I), (e) (II) and (f) (III), the distances from a surface point to the nearest interior/exterior atoms $\left(d_{\mathrm{i} / \mathrm{e}}\right)$ are given in $\AA$. 
Table 4

Percentage Hirshfeld surface area for which the closest contact is of the type atom $1 \cdots$ atom 2 .

\begin{tabular}{lrrr}
\hline Contact type & (I) & \multicolumn{1}{c}{ (II) } & (III) \\
\hline O $\cdots \mathrm{C}$ & $2.0 \%$ & $0.7 \%$ & $2.0 \%$ \\
$\mathrm{O} \cdots \mathrm{H}$ & $17.8 \%$ & $21.8 \%$ & $12.6 \%$ \\
$\mathrm{~N} \cdots \mathrm{C}$ & $0.4 \%$ & $2.2 \%$ & $1.9 \%$ \\
$\mathrm{~N} \cdots \mathrm{H}$ & $0.8 \%$ & $10.7 \%$ & $7.1 \%$ \\
$\mathrm{C} \cdots \mathrm{C}$ & $1.7 \%$ & $5.7 \%$ & $3.4 \%$ \\
$\mathrm{C} \cdots \mathrm{H}$ & $32.8 \%$ & $24.8 \%$ & $25.1 \%$ \\
$\mathrm{H} \cdots \mathrm{H}$ & $44.5 \%$ & $34.1 \%$ & $47.8 \%$ \\
\hline
\end{tabular}

corresponds to a region with weak contacts and a bluecoloured region is considered to be free of significant contacts.

Comparing Figs. 2(a)-(c) with $3(a)-(c)$ - the electron density with the function $d_{\text {norm }}$ plotted on the Hirshfeld surfaces - the $\mathrm{O}-\mathrm{H} \cdots \mathrm{O} / \mathrm{N}$ hydrogen bonds can still be located at the same positions on the Hirshfeld surfaces. However, the function $d_{\text {norm }}$ is more sensitive in revealing the weak $\mathrm{C}-\mathrm{H}$ - acceptor interactions. There are several localized contact areas coloured red or white on the Hirshfeld surfaces of (I)-(III). However, (II) (Fig. 3b) exhibits less localized but broad contact areas on top of the aromatic rings in contrast to (I) and (III). A sixfold net structure of faint blue lines is visible on these areas of (II), which is typical for $\pi \cdots \pi$ interactions. This is almost invisible on the Hirshfeld surfaces of (I) and (III).

If the values of $d_{\mathrm{i}}$ and $d_{\mathrm{e}}$ for any Hirshfeld surface point are directly plotted against each other, so-called fingerprint plots can be generated, see Figs. 3(d)- $(f)$, which show typical motifs and thus reveal the individual interaction types present (Spackman \& Jayatilaka, 2009). The fingerprints of (I) and (III) are rather similar, but that of (II) differs again. It exhibits more features characteristic of certain contacts, but also shows that there are more voids in the crystal packing. By reducing the fingerprints to plots only including a chosen contact of the type atomtype 1 ...atomtype 2 , it is possible to allocate the fingerprint features to these individual types of contacts [demonstrated for (II) in Figs. $4 a-f$ )] and obtain a percentage surface coverage for the individual interaction types (see Table 4).

The closest contacts in (II) giving rise to the typical long spikes in the fingerprints are due to the $\mathrm{O}-\mathrm{H} \cdots \mathrm{N}$ interactions (Fig. 4a). Correspondingly, the spikes in the fingerprints of (I) and (III) (Figs. $3 d$ and $f$ ) belong to the closest $\mathrm{O}-\mathrm{H} \cdots \mathrm{O}$ contacts. In (II) close $\mathrm{H} \cdots \mathrm{O}$ contacts stemming from $\mathrm{C}-$ $\mathrm{H}$.. O hydrogen bonds give rise to additional smaller spikes in

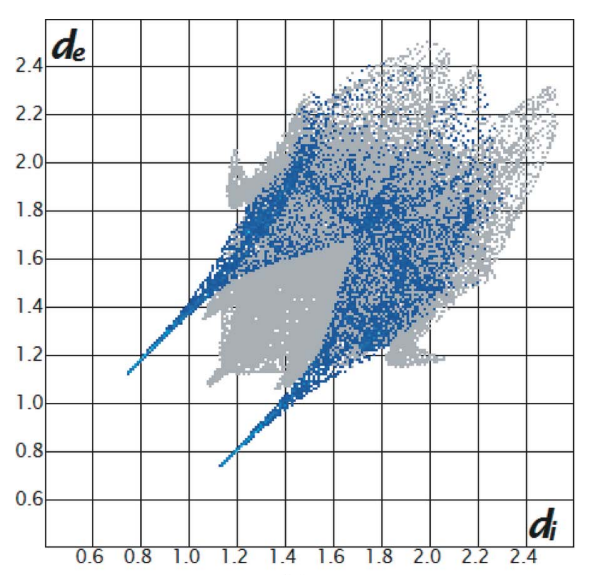

(a)

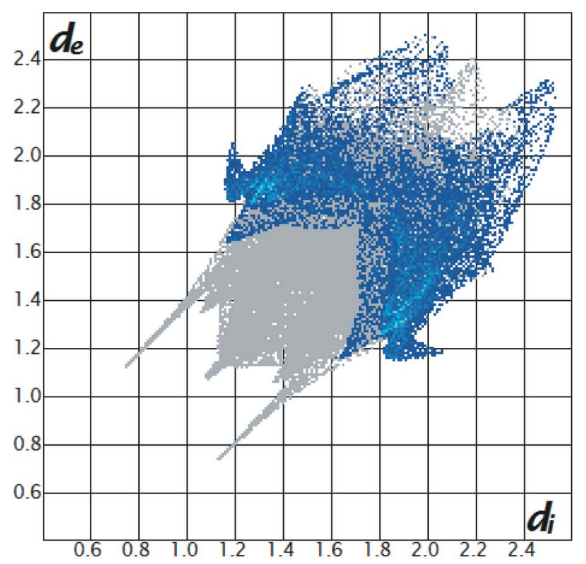

(d)

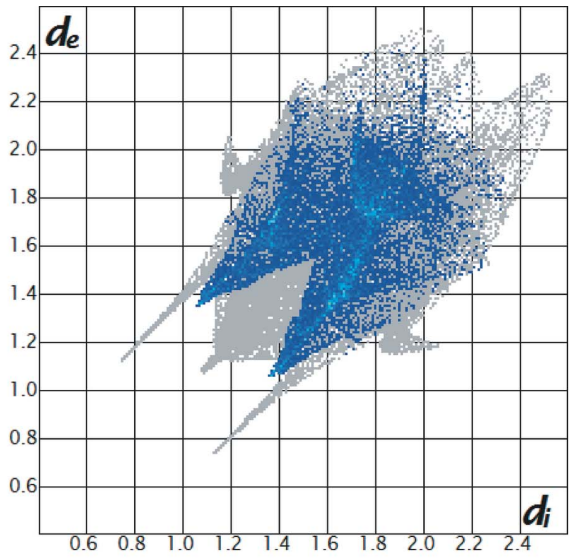

(b)

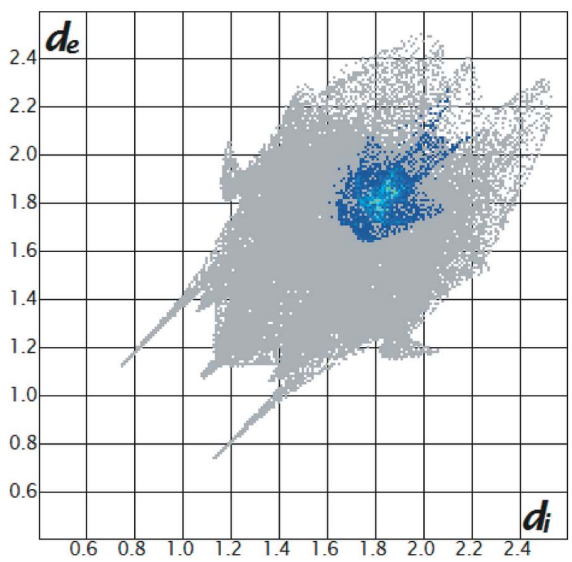

(e)

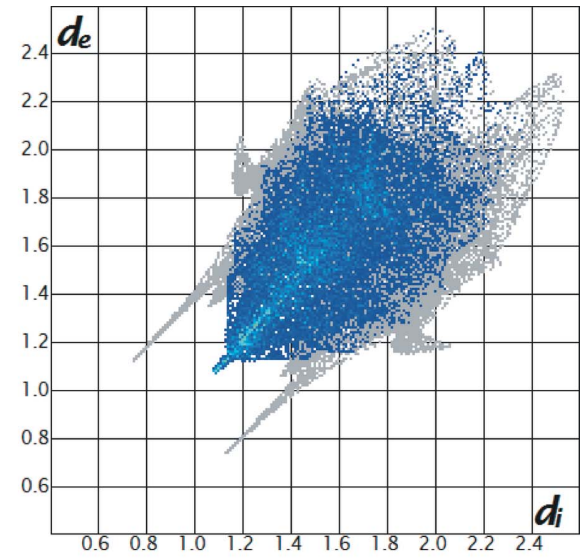

(c)

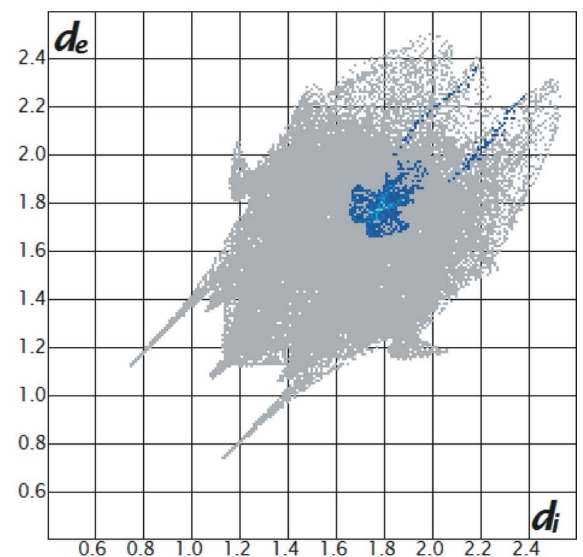

$(f)$

Figure 4

Fingerprint plot of (II) reduced to a given contact type atom1 $\cdots$ atom2: $(a)$ contact $\mathrm{H} \cdots \mathrm{N} ;(b)$ contact $\mathrm{H} \cdots \mathrm{O} ;(c)$ contact $\mathrm{H} \cdots \mathrm{H} ;(d)$ contact $\mathrm{C} \cdots \mathrm{H} ;(e)$ contact C...C; $(f)$ contact $\mathrm{N} \cdots \mathrm{C}$. 
Table 5

A representative selection of weak intermolecular interactions in the crystal lattice of (II).

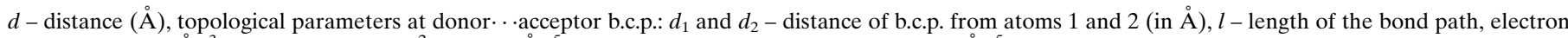
density $\rho(r)\left(\right.$ in e $\AA^{-3}$ ) and its Laplacian $\nabla^{2} \rho(r)$ (in e $\left.\AA^{-5}\right), \lambda_{1}, \lambda_{2}, \lambda_{3}$ - eigenvalues of Hessian (in e $\AA^{-5}$ ), $\varepsilon$ - ellipticity, local energy densities $-G(r), V(r), H(r)($ in $\mathrm{kJ} \mathrm{mol}^{-1}$ per atomic unit volume), $|V| / G$ - ratio of the potential and kinetic energy density at the b.c.p. obtained from exp multipole model of (II) (first line) and corresponding theoretical $t h-s p$ model (second line).

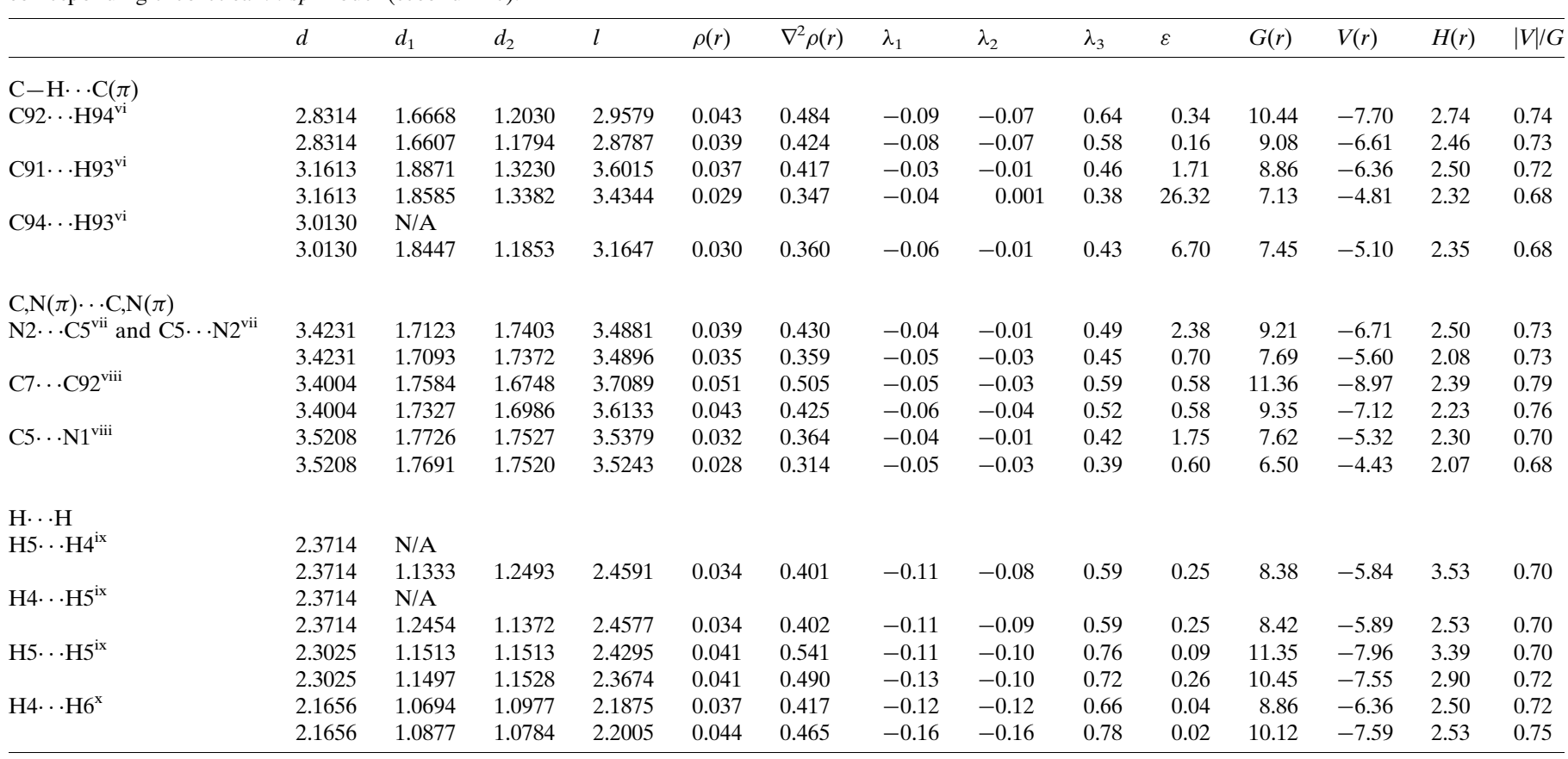

Symmetry codes: (vi) $1-x, y-\frac{1}{2}, \frac{1}{2}-z$; (vii) $-x,-y,-z$; (viii) $x, y-1, z$; (ix) $-x,-1-y,-z ;$ (x) $x,-\frac{1}{2}-y,-\frac{1}{2}+z$.

the fingerprint plot (Fig. 4b). Besides the closest contacts leading to the spikes, there are many points on the Hirshfeld surfaces for which the $\mathrm{H} \cdots \mathrm{N}$ and $\mathrm{H} \cdots \mathrm{O}$ contacts are those with the shortest contact distance, although the contact distances can become as long as $4 \AA$. The $d_{\text {norm }}$ values for these contacts would not have led to a red or white colouring of the surface, but they contribute to the overall percentage surface area, for which the closest contact is of the type $\mathrm{H} \cdots \mathrm{O}$ or $\mathrm{H} \cdots \mathrm{N}, c f$. Table 4 . There is $13-22 \%$ of the surface area of (I)-(III) covered by $\mathrm{O} \cdots \mathrm{H}$ contacts. For the isoindole derivative (I) the $\mathrm{H} \cdots \mathrm{N}$ contacts cover only $0.8 \%$. For the azaisoindole derivatives (II) and (III), comprising an additional nitrogen acceptor atom, the values are 10.7 and $7.1 \%$. Although there is an $\mathrm{O}-\mathrm{H} \cdots \mathrm{N}$ hydrogen bond in (II) but not in (III), the percentage surface area covered is not significantly different. This shows that the characteristic features in the fingerprint plots allow the identification of close contacts which are important to build the crystal-packing network, but the information on the percentage surface area coverage is complementary information on how the total contacts are shared among each other.

Fig. 4(c) shows that $\mathrm{H} \cdots \mathrm{H}$ contacts are very common as contacts with the shortest distance on the surface. They make up to $50 \%$ of all contacts (see Table 4), which is due to the small van der Waals radius of hydrogen. They can come closer in a packing than larger atoms and thus are the closest contacts due to mechanical necessities where there are no attractive interactions between donors and acceptors. However, there is a small spike in the fingerprint plot of (II) (Figs. $3 e$ and $4 c$ ) in contrast to (I) and (III) (Figs. $3 d$ and $f$ ) which stems from a very close $\mathrm{H} \cdot \cdots \mathrm{H}$ contact $(\sim 2.2 \AA)$. As there is a recent controversial discussion in the literature on the existence or non-existence of attractive $\mathrm{H} \cdots \mathrm{H}$ interactions in general (Farrugia et al., 2009; Grabowski, 2011, and references therein) the $\mathrm{H} \cdots \mathrm{H}$ contact found with the help of the Hirshfeld method will be discussed in detail below using a topological analysis.

$\mathrm{H}$.. C interactions are also common contacts covering about $25 \%$ of the Hirshfeld surface areas of (I)-(III) (see Table 4). However, there are further close contacts giving rise to characteristic features in the fingerprint plots. The chickenwing-like features in the fingerprint plot of (II) (Fig. 4d) are typical and characteristic of $\mathrm{C}-\mathrm{H} \cdots \pi$ interactions, where the $\pi$-system is represented by the $\mathrm{C}$ atoms of the aromatic rings (therefore H..C contacts; Spackman \& Jayatilaka, 2009). These features and thus $\mathrm{C}-\mathrm{H} \cdots \pi$ interactions are also present in the fingerprint plots of (I) and (III) (Figs. $3 d$ and $f$ ), but not so pronounced.

The central marker present in the fingerprint plot of (II) (Fig. 3e) is a typical and characteristic hint towards significant $\pi \cdots \pi$ interactions (Spackman \& Jayatilaka, 2009). It is formed by $\mathrm{C} \cdots \mathrm{C}$ and $\mathrm{C} \cdots \mathrm{N}$ interactions likewise which represent the $\pi \cdots \pi$ interactions (see Figs. $4 e$ and $f$ ). This central marker is missing in the fingerprint plots of (I) and (III) showing that 
$\pi \cdots \pi$ interactions are much more important in the packing of (II). Table 4 shows that the percentage Hirshfeld surface area covered by $\mathrm{C} \cdots \mathrm{C}$ and $\mathrm{C} \cdots \mathrm{N}$ contacts is largest for (II) with 5.7 and $2.2 \%$, but that these interactions are also present in the other two compounds.

Analysis of the fingerprint plots and Hirshfeld surfaces has shown that - besides the $\mathrm{O}-\mathrm{H} \cdots \mathrm{N}$ and $\mathrm{C}-\mathrm{H} \cdots \mathrm{O}$ hydrogen bonds already discussed - (II) is rich of all different kinds of weak interactions, namely close $\mathrm{H} \cdots \mathrm{H}, \mathrm{C}-\mathrm{H} \cdots \pi$ and $\pi \cdots \pi$ interactions. $\mathrm{C}-\mathrm{H} \cdots \pi$ interactions are also present in the packings of (I) and (III), but $\pi \cdots \pi$ interactions are only very limited.

We decided to study the electron-density topology of the weak $\mathrm{C}-\mathrm{H} \cdots \pi, \pi \cdots \pi$ and $\mathrm{H} \cdots \mathrm{H}$ interactions by using the experimental results and additionally by calculating dimers or trimers of symmetry-related molecules at the experimental geometry to approximate the interactions present in the crystal in the theoretical case. We concentrated on (II) as this azaisoindole gives access to the whole spectrum of interactions. Table 5 gives a selection of $\mathrm{C}-\mathrm{H} \cdots \mathrm{C}(\pi), \mathrm{C}(\pi) \cdots \mathrm{C}(\pi)$,
$\mathrm{C}(\pi) \cdots \mathrm{N}(\pi)$ and $\mathrm{H} \cdots \mathrm{H}$ interactions for which a b.c.p. with a corresponding bond path could be found. Some of them can only be found in the theoretical calculations, but not in the crystal lattice, see discussion on this phenomenon for $\mathrm{H} \cdots \mathrm{H}$ contacts below. Fig. 5 visualizes the relevant interactions of the dimers and trimers showing bond, ring and cage critical points as well as the bond paths. As was already suggested by the fingerprint plots using geometrical criteria, $\mathrm{C}-\mathrm{H} \cdots \pi$ and $\pi \cdots \pi$ interactions manifest themselves as close contacts between individual atom pairs also in the topology of the electron density. For example, $\mathrm{C}-\mathrm{H} \cdots \pi$ interactions between a symmetry-related pair of molecules, in which two of the $\mathrm{H}$ atoms of one phenyl ring point nearly perpendicularly to the ring plane of another phenyl ring (Fig. 5a), are expressed by only three bond paths for the dimer calculation and only two bond paths in the experimental density. The first part of Table 5 shows that the distances between donor and acceptor atoms are $\sim 3 \AA$ and thus by $\sim 0.5 \AA$ longer than for $\mathrm{C}-\mathrm{H} \cdots \mathrm{O}$ interactions ( $c f$. Table 3 ). The values of the electron density and the Laplacian at the b.c.p. are accordingly slightly lower

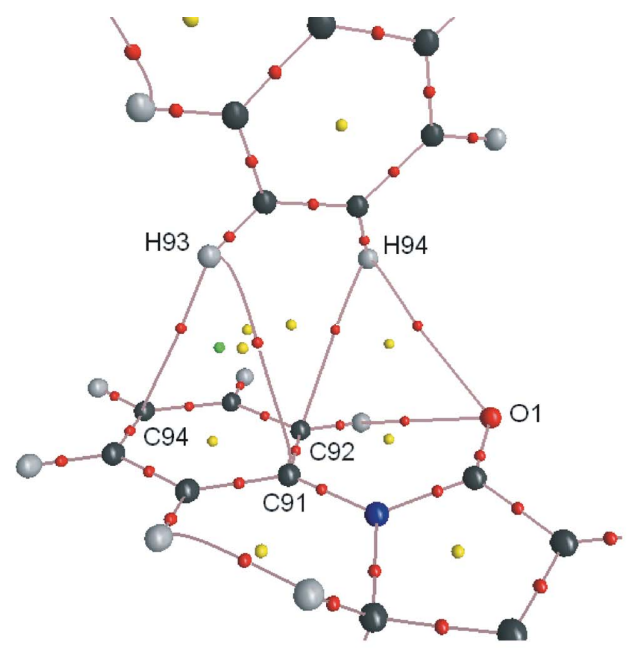

(a)

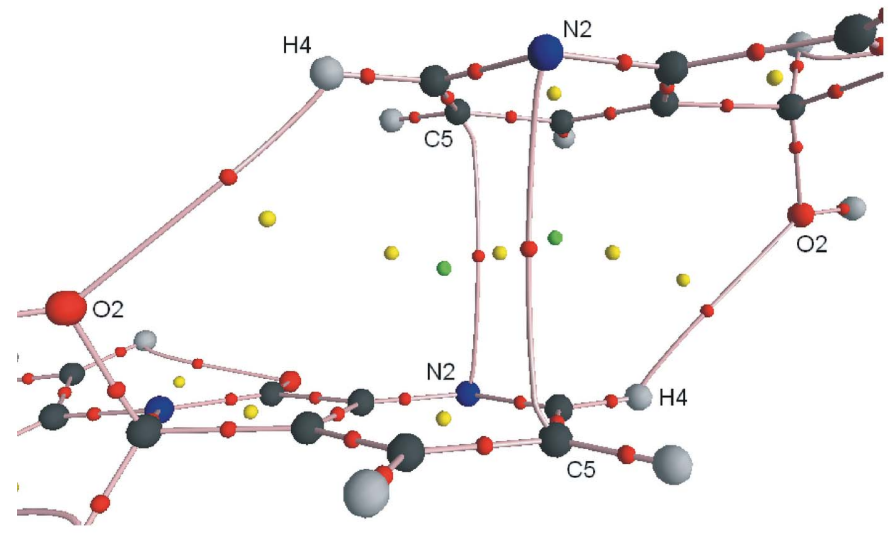

(c)

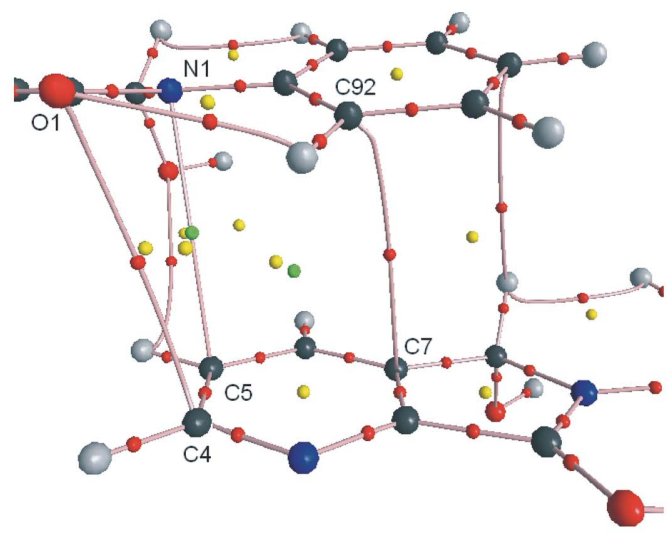

(b)

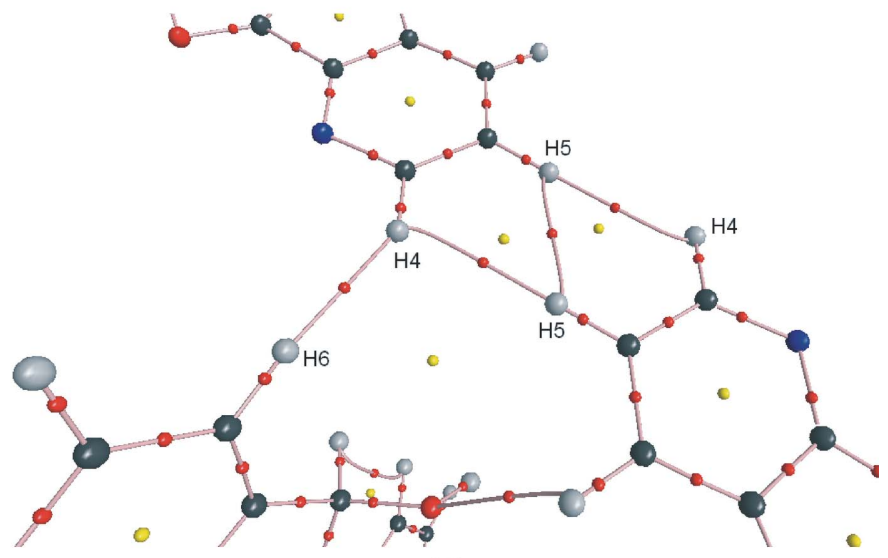

(d)

Figure 5

Molecular graphs of weak intermolecular interactions from theoretical calculations of dimers and trimers at the experimental geometry of (II): $(a) \mathrm{C}-$ $\mathrm{H} \cdots \mathrm{C}(\pi)$ interactions (symmetry: $\left.1-x, y-\frac{1}{2}, \frac{1}{2}-z\right) ;(b) \mathrm{C}(\pi) \cdots \mathrm{C}, \mathrm{N}(\pi)$ interactions (symmetry: $\left.x, y-1, z\right) ;(c) \mathrm{C}(\pi) \cdots \mathrm{N}(\pi)$ interactions $($ symmetry: $-x,-y,-z) ;(d) \mathrm{H} \cdots \mathrm{H}$ interactions (symmetry: $-x,-1-y,-z ; x,-\frac{1}{2}-y,-\frac{1}{2}+z$ ). The positions of the bond, ring and cage critical points are shown as small red, yellow and green spheres. 
than for $\mathrm{C}-\mathrm{H} \cdots \mathrm{O}$ interactions. The differences are more pronounced in values of local energy densities, which are about half those found for interactions of the $\mathrm{C}-\mathrm{H} \cdots \mathrm{O}$ type. Moreover, for the long weak interactions the sum of the distances $d_{1}$ and $d_{2}$ is $\sim 0.03-0.05 \AA$ longer than the direct distance $d$, whereas the total bond path length $l$ is significantly longer than $d$ up to $0.4 \AA$. For a strained and curved bananatype bond such as that occurring in epoxides, the difference between direct bond distance and bond path length is only $\sim 0.01-0.02 \AA$ for both $\mathrm{C}-\mathrm{O}$ and $\mathrm{C}-\mathrm{C}$ bonds (Grabowsky et al., 2010).

$\pi \cdots \pi$ interactions are mainly guided by $\mathrm{C} \cdots \mathrm{N}$ bond paths. The molecules arrange in a way that $\mathrm{C} \cdots \mathrm{N}$ contacts can be generated connecting two aromatic ring systems (see Figs. $5 b$ and $c$ ), which might be favoured compared with $\mathrm{C} \cdots \mathrm{C}$ contacts due to the electronegativity difference. However, there is one $\mathrm{C}(\pi) \cdots \mathrm{C}(\pi)$ contact $(\mathrm{C} 7 \ldots \mathrm{C} 92)$ shown in Fig. $5(b)$, which is shorter than the $\mathrm{C} \cdots \mathrm{N}$ contacts, has higher values of the electron density and the corresponding Laplacian at the b.c.p. and energies (see second part of Table 5). Although the distances of the $\mathrm{C}(\pi) \cdots \mathrm{C}, \mathrm{N}(\pi)$ contacts are $\sim 3.5 \AA$ and thus longer than the $\mathrm{C}-\mathrm{H} \cdots \pi$ contacts, the values of the electron density, the Laplacian and the local energy densities are very similar, so that it can be followed that both interaction types are of similar strength. Furthermore, the dependencies between contact distance $d$, the sum of $d_{1}$ and $d_{2}$ and bond path length $l$ are also similar, which confirms the curved shape of the bond paths describing $\mathrm{C}-$ $\mathrm{H} \cdots \pi$ as well as $\pi-\pi$ interactions. There are additional $\mathrm{O} \cdots \mathrm{C}(\pi)$ contacts in the crystal packing and in the dimers connecting the carbonyl and hydroxyl groups with the aromatic rings (see e.g. contact $\mathrm{O} 1 \cdots \mathrm{C} 4$ shown in Fig. $5 b$ ).

It is true for all $\mathrm{C}-\mathrm{H} \cdots \pi$ and $\pi \cdots \pi$ contacts listed in Table 5 that the electron density and the Laplacian at the b.c.p. are higher if derived from the experiment which takes into account the complete crystal lattice. The same tendency is found for energetic parameters, which, in principle, depend on the topological parameters. This can be interpreted as the interactions being stronger in the crystal, which might be due to a mutual strengthening of the intermolecular interactions by the complete pattern of interactions. It cannot be due to geometrical effects as the experimental geometries have been used for the calculations of the dimers and hence the direct contact distances are identical.

It has been discussed above that $\sim 50 \%$ of all the closest contacts are $\mathrm{H} \cdots \mathrm{H}$ contacts and that there are a few remarkably short ones in (II). Table 5 lists them and Fig. 5(d) visualizes them for a trimer containing all of them found in the

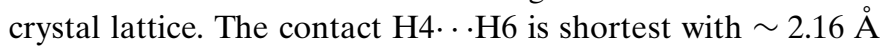
between the $\mathrm{H}$ atoms, the contact $\mathrm{H} 5 \cdots \mathrm{H} 5$ is second shortest with $2.30 \AA$, and the contact $\mathrm{H} 4 \ldots \mathrm{H} 5$ is still considerably short with about $2.37 \AA$. B.c.p.s and corresponding bond paths can be found for all of these three different $\mathrm{H} \cdots \mathrm{H}$ contacts within the theoretical trimer calculation. However, in the experiment, only the b.c.p.s for $\mathrm{H} 5 \cdots \mathrm{H} 5$ and $\mathrm{H} 4 \cdots \mathrm{H} 6$ contacts and the corresponding bond paths can be found but

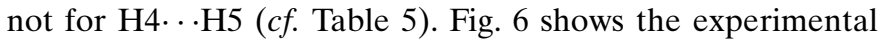

gradient vector field in the plane containing all $\mathrm{H} \cdots \mathrm{H}$ contacts. It is obvious that the gradient trajectories are oriented to allow a bond path to be formed between $\mathrm{H} 5 \cdots \mathrm{H} 5$ and $\mathrm{H} 4 \cdots \mathrm{H} 6$, but not $\mathrm{H} 4 \cdots \mathrm{H} 5$. However, whenever two atoms share a zero-flux surface, i.e. generate an interatomic surface, there must be a b.c.p. and a corresponding bond path between them (Gatti, 2005; Popelier \& Logothetis, 1998). There are only some very exotic cases where this is not true (Cassam-Chenaï \& Jayatilaka, 2000). However, in a crystal, especially in regions with weak intermolecular interactions such as $\mathrm{H} \cdots \mathrm{H}$ contacts, it is very common that atomic basins seem to touch each other by visual inspection of any appropriate two- or three-dimensional plot without giving rise to a bond path. Also, neighbouring $\mathrm{H}$ atoms in molecules do not normally give rise to a bond path, although their atomic basins seem to touch each other (for example in simple molecules such as benzene or water at some distance from the $\mathrm{O}$ or $\mathrm{C}$ atoms). The explanation is that the two atomic basins are infinitesimally close to each other, physically and visually indistinguishable, but they do not mathematically share a common zero-flux surface; they do not have an interatomic surface (Gatti, 2005; Popelier \& Logothetis, 1998). Therefore, the absence of a b.c.p. between H4 and H5 does not exclude the fact that their atomic basins physically (but not mathematically) touch each other. Therefore, Fig. 6 exemplifies a case where a weak intermolecular $\mathrm{H} \cdot \cdot \mathrm{H}$ contact is exactly on the borderline between forming or not forming an interatomic surface between two $\mathrm{H}$ atoms. A very slight difference in the electron-density distribution (theory $v s$ experiment) at the same geometry leads to the appearance or disappearance of the bond path. It is not clear if the missing $\mathrm{H} 4 \cdots \mathrm{H} 5$ bond path is a hint towards a repulsive description of the $\mathrm{H} \cdots \mathrm{H}$ interaction in general or the appearance of a bond path a hint towards an attractive description (see the debate in the literature: Farrugia et al., 2009; Grabowski, 2011, and refer-

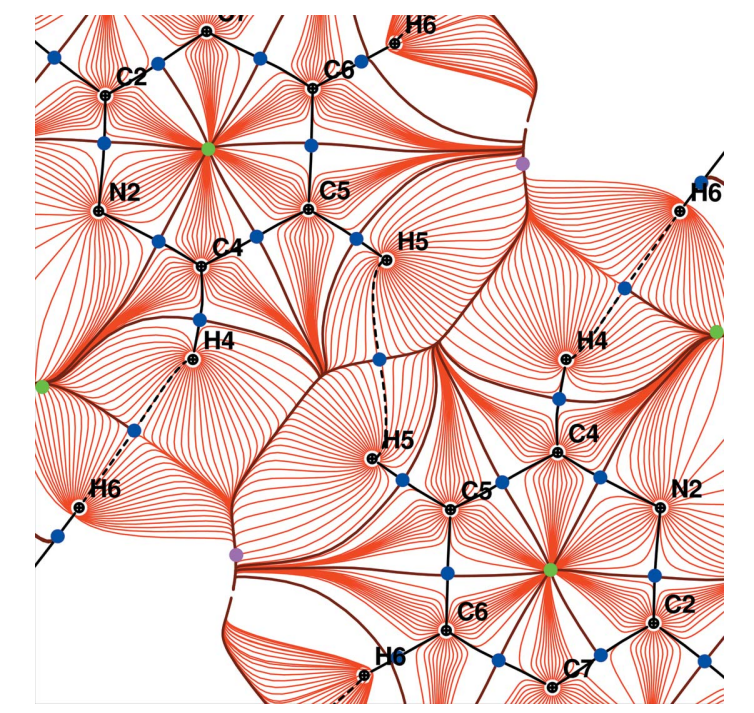

Figure 6

Experimental gradient-vector field in the plane of the $\mathrm{H} \cdots \mathrm{H}$ contacts, bond paths between $\mathrm{H} 4 \cdots \mathrm{H} 6$ and $\mathrm{H} 5 \cdots \mathrm{H} 5$ are plotted, but there are no bond paths between $\mathrm{H} 4$ and $\mathrm{H} 5$ (in contrast to the theory, $c f$. Fig. $5 d$ ). 
ences therein). There are only a few studies analysing $\mathrm{H} \cdots \mathrm{H}$ interactions of the type $\mathrm{H}$ (protic) .. $\mathrm{H}$ (hydridic) (Mebs et al., $2010,2011)$, but also of the type $\mathrm{H}$ (neutral) $\cdots \mathrm{H}$ (neutral) (Matta et al., 2003; Hernández-Trujillo \& Matta, 2007). It must be noticed that, in our example, there is a bond path between two exactly identically polarized $\mathrm{H}$ atoms $(\mathrm{H} 5 \cdots \mathrm{H} 5)$ and none between at least slightly differently polarized $\mathrm{H}$ atoms ( $\mathrm{H} 4$ being closer to an $\mathrm{N}$ atom than $\mathrm{H} 5$ ). The values of the electron density, the Laplacian and the energy densities at the $\mathrm{H} \cdots \mathrm{H}$ b.c.p.s (Table 5) are in the same range as found for the $\mathrm{C}-$ $\mathrm{H} \cdots \pi$ and $\pi \cdots \pi$ interactions above showing that $\mathrm{H} \cdots \mathrm{H}$ interactions are likewise strong. Compared with electrondensity values of interactions of the type $\mathrm{H}$ (protic) . . H(hydridic) found in the literature (Mebs et al., 2010, 2011), it can be stated that the $\mathrm{H} \cdot \mathrm{*H}$ interactions found here are slightly weaker.

\section{Conclusions}

We have determined the electron-density distributions of three (aza)isoindole derivatives using models based on the multipole formalism, and compared the results throughout with the analogous properties determined by theoretical calculations. This study indicates that the topological and atomic properties of all three (aza)isoindole derivatives in the solid state are in reasonable agreement with those determined in the gas phase by $D F T$ calculations.

The use of Bader's AIM theory allows us to obtain a topological description of the weak intermolecular $\mathrm{C}-$ $\mathrm{H} \cdots \mathrm{C}(\pi), \mathrm{C}, \mathrm{N}(\pi) \cdots \mathrm{C}, \mathrm{N}(\pi)$ and $\mathrm{H} \cdots \mathrm{H}$ interactions, which were compared with conventional hydrogen bonds. Interactions with the $\pi$-systems are represented by close contacts between individual atoms of these systems visible by bond paths in the electron density, but also as characterized by purely geometrical means. The interactions involving $\pi$-electrons as well as the $\mathrm{H} \cdots \mathrm{H}$ interactions were shown to be only slightly weaker than $\mathrm{C}-\mathrm{H} \cdots \mathrm{O}$ interactions, although their bond paths are extremely curved and thus significantly longer than the direct bond distance (up to $0.6 \AA$ ). There are three different remarkably short $\mathrm{H} \cdots \mathrm{H}$ contacts in (II) (2.16$2.37 \AA$ ) between partially positively polarized $\mathrm{H}$ atoms bonded to a $\mathrm{C}$ atom. In the theoretical trimer calculation based on the experimental crystal geometry, all bond paths can be found in contrast to the experiment. An analysis of the experimental gradient-vector field shows that the gradient vectors are oriented in one case to give rise to a b.c.p. and a corresponding bond path, but are oriented in another case to give rise to neither b.c.p. nor bond path. The differentiation between attractive and repulsive types of $\mathrm{H} \cdots \mathrm{H}$ interactions is of recent debate in the literature and it seems that subtle differences in the density (experiment versus theory in this study) cause the character of the interaction to change fundamentally.

Moreover, it was shown that from a Hirshfeld surface analysis it is possible to easily identify all close contacts and distinguish them from each other. Nearly $50 \%$ of all contacts between two atoms being closest to a Hirshfeld surface point are made up of $\mathrm{H} \cdots \mathrm{H}$ contacts, whereas $\mathrm{C} \cdot \mathrm{H}$ contacts account for $25 \%$. These contacts can be as long as $4 \AA$, whereas the overall closest contacts below $2.5 \AA$ which guide the crystal packing can be found using typical features in fingerprint plots. By mapping the total aspherical electron density and the electrostatic potential on the Hirshfeld surface, covalent and electrostatic contributions of the hydrogen bonds can be distinguished from each other. Analysis of the complete intermolecular interaction pattern of the (aza)isoindole fragments is especially important as they occur in various biologically active compounds and the lowmolecular-weight ligand-enzyme recognition process is guided by long-range interactions as discussed here.

Thus, the experimental electron-density determination supported by theoretical calculations can be used to understand the nature of the complete interaction pattern of biologically important compounds involving weak $\pi$-interactions and $\mathrm{H} \cdot \mathrm{H}$ contacts.

The high-resolution measurements were carried out within the project I-20090042 EC at the light source DORIS III at HASYLAB/DESY, Hamburg, Germany. The research leading to these results has received funding from the European Community's Seventh Framework Programme (FP7/20072013) under grant agreement No. 226716 and from the Australian Research Council within the Discovery Project DP110105347. Professor Dylan Jayatilaka is gratefully acknowledged for stimulating discussions and his help with the program CrystalExplorer. We would also like to thank Professor Carlo Gatti for his explanations and clarifications concerning interatomic surfaces in the electron-density topology. We also thank the Academic Computer Centre CYFRONET AGH and the supercomputer center of ZEDAT of Freie Universität Berlin for the use of computational facilities. We are very grateful to Agilent Technologies for $\mathrm{Cu} K \alpha$ data collection of (III).

\section{References}

Allen, F. H., Watson, D. G., Brammer, L., Orpen, A. G. \& Taylor, R. (2006). International Tables for X-ray Crystallography, Vol. C, Ch. 9.5. pp. 790-811. Heidenberg: Springer.

American Home Products Corporation (1997). US Patent EP566567 B1.

Anzini, M., Cappelli, A., Vomero, S., Giorgi, G., Langer, T., Bruni, G., Romeo, M. R. \& Basile, A. S. (1996). J. Med. Chem. 39, 4275-4284.

Bader, R. F. W. (1990). Atoms in Molecules: A Quantum Theory. Oxford: Clarendon Press.

Bader, R. F. W., Carroll, M. T., Cheeseman, J. R. \& Chang, C. (1987). J. Am. Chem. Soc. 109, 7968-7979.

Bader, R. F. W., Slee, T. S., Cremer, D. \& Kraka, E. (1983). J. Am. Chem. Soc. 105, 5061-5068.

Bernstein, J., Davis, R. E., Shimoni, L. \& Chang, N.-L. (1995). Angew. Chem. Int. Ed. Engl. 34, 1555-1573.

Biegler-König, F. \& Schönbohm, J. (2002). J. Comput. Chem. 23, 1489-1494.

Broussy, S., Bernardes-Génisson, V., Gornitzka, H., Bernadou, J. \& Meunier, B. (2005). Org. Biomol. Chem. 3, 666-669.

Bruker (2005). XPREP. Bruker AXS Inc., Madison, Wisconsin, USA. 
Burnett, M. N. \& Johnson, C. K. (1996). ORTEPIII, Report ORNL6895. Oak Ridge National Laboratory, Oak Ridge, Tennessee, USA.

Cassam-Chenaï, P. \& Jayatilaka, D. (2000). Theor. Chem. Acc. 105, 213-218.

Connolly, M. L. (1983). J. Appl. Cryst. 16, 548-558.

Coppens, P., Abramov, Y., Carducci, M., Korjov, B., Novozhilova, I., Alhambra, C. \& Pressprich, M. R. (1999). J. Am. Chem. Soc. 121, 2585-2593.

Espinosa, E., Alkorta, I., Elguero, J., Molins, E. \& Lecomte, C. (2002). J. Chem. Phys. 117, 5529-5542.

Espinosa, E., Molins, E. \& Lecomte, C. (1998). Chem. Phys. Lett. 285, 170-173.

Farrugia, L. J., Kočovský, P., Senn, H. M. \& Vyskočil, Š. (2009). Acta Cryst. B65, 757-769.

Frisch, M. J. et al. (2004). GAUSSIAN03, Revision E. 01. Gaussian Inc., Wallingford CT, USA.

Gatti, C. (2005). Z. Kristallogr. 220, 399-457.

Gotor, V., Limeres, R., Garcia, R., Bayod, M. \& Brieva, R. (1997). Tetrahedron Asymmetry, 8, 995-997.

Grabowski, S. J. (2011). Chem. Rev. 111, 2597-2625.

Grabowsky, S., Jayatilaka, D., Mebs, S. \& Luger, P. (2010). Chem. Eur. J. 16, 12818-12821.

Grabowsky, S., Kalinowski, R., Weber, M., Förster, D., Paulmann, C. \& Luger, P. (2009). Acta Cryst. B65, 488-501.

Hansen, N. K. \& Coppens, P. (1978). Acta Cryst. A34, 909-921.

Hernández-Trujillo, J. \& Matta, C. F. (2007). Struct. Chem. 18, 849857.

Hübschle, C. B. \& Dittrich, B. (2011). J. Appl. Cryst. 44, 238240.

Kabsch, W. (1993). J. Appl. Cryst. 26, 795-800.

Kabsch, W. (2010). Acta Cryst. D66, 125-132.

Keith, T. A. (2009). AIMall, Version 09.10.24, http://aim.tkgristmill.com.

Krygowski, T. M. (1993). J. Chem. Inf. Comput. Sci. 33, 70-78.

Madsen, A. Ø. (2006). J. Appl. Cryst. 39, 757-758.

Matta, C. F., Hernández-Trujillo, J., Tang, T. H. \& Bader, R. F. W. (2003). Chem. Eur. J. 9, 1940-1951.
McKinnon, J. J., Jayatilaka, D. \& Spackman, M. A. (2007). Chem. Commun. pp. 3814-3816.

McKinnon, J. J., Spackman, M. A. \& Mitchell, A. S. (2004). Acta Cryst. B60, 627-668.

Mebs, S., Grabowsky, S., Förster, D., Kickbusch, R., Hartl, M., Daemen, L. L., Morgenroth, W., Luger, P., Paulus, B. \& Lentz, D. (2010). J. Phys. Chem. A, 114, 10185-10196.

Mebs, S., Kalinowski, R., Grabowsky, S., Förster, D., Kickbusch, R., Justus, E., Morgenroth, W., Paulmann, C., Luger, P., Gabel, D. \& Lentz, D. (2011). J. Phys. Chem. A, 115, 1385-1395.

Mladenovic, M., Arnone, M., Fink, R. F. \& Engels, B. (2009). J. Phys. Chem. B, 113, 5072-5082.

Munshi, P. \& Row, T. N. G. (2006). Acta Cryst. B62, 612-626.

Naray-Szabo, G. \& Ferenczy, G. G. (1995). Chem. Rev. 95, 829-847.

Palusiak, M. \& Krygowski, T. M. (2009). New J. Chem. 33, 1753-1759.

Paulmann, C. \& Morgenroth, W. (2006). Hasylab Jahresbericht I, pp. 1121-1122.

Popelier, P. L. A. \& Logothetis, G. (1998). J. Organomet. Chem. 555, 101-111.

Sheldrick, G. M. (2008). Acta Cryst. A64, 112-122.

Sorbera, L. A., Leeson, P. A., Silvestre, J. \& Castaner, J. (2001). Drugs of the Future, 26, 651.

Spackman, M. A. \& Byrom, P. G. (1997). Chem. Phys. Lett. 267, 215220.

Spackman, M. \& Jayatilaka, D. (2009). CrystEngComm, 11, 19-32.

Spackman, M. A., McKinnon, J. J. \& Jayatilaka, D. (2008). CrystEngComm, 10, 377-388.

Szatyłowicz, H., Krygowski, T. M., Palusiak, M., Poater, J. \& Solà, M. (2011). J. Org. Chem. 76, 550-556.

Volkov, A. \& Coppens, P. (2001). Acta Cryst. A57, 395-405.

Volkov, A., Gatti, C., Abramov, Y. \& Coppens, P. (2000). Acta Cryst. A56, 252-258.

Volkov, A., Macchi, P., Farrugia, L. J., Gatti, C., Mallinson, P. R., Richter, T. \& Koritsanszky, T. (2006). XD2006, Version 5.42. University of New York at Buffalo, USA.

Wada, T. \& Fukuda, N. (1991). Psychopharmacology, 103, 314-322.

Weber, M., Grabowsky, S., Hazra, A., Naskar, S., Banerjee, S., Mondal, N. B. \& Luger, P. (2011). Chem. Asian J. 6, 1390-1397. 